\title{
Subsecond fear discrimination in rats: adult impairment in adolescent heavy alcohol drinkers
}

\author{
Alyssa DiLeo, Kristina M. Wright, and Michael A. McDannald \\ Department of Psychology, Boston College, Chestnut Hill, Massachusetts 02467, USA
}

\begin{abstract}
Discriminating safety from danger must be accurate and rapid. Yet, the rapidity with which fear discrimination emerges remains unknown. Rapid fear discrimination in adulthood may be susceptible to impairment by adolescent heavy alcohol drinking, which increases incidence of anxiety disorders. Rats were given voluntary, adolescent alcohol access, and heavy drinkers were identified. In adulthood, rapid fear discrimination of safety, uncertainty, and danger cues was assessed. Normal rats, but not heavy drinkers, showed discriminative fear $<1$ sec following cue onset. This provides the first demonstration of subsecond fear discrimination and its adult impairment in adolescent heavy alcohol drinkers.
\end{abstract}

[Supplemental material is available for this article.]

The ability to discriminate cues predicting safety from cues predicting danger is vital. Given the importance, it is not surprising that people and rats normally discriminate such cues accurately (Schiller et al. 2008; McDannald 2010). However, people with anxiety disorders, such as post-traumatic stress disorder (PTSD), are markedly impaired at fear discrimination, showing inappropriate fear to safety cues (Jovanovic et al. 2010, 2011). Fear discrimination should not only be accurate but should also emerge rapidly following encounters. When walking home late, it is more beneficial to notice that a street is poorly lit immediately turning onto it, rather than halfway down it. Yet, the fundamental question of how rapidly fear discrimination emerges following cue onset, in people or rats, remains unanswered.

PTSD and alcohol use disorders are highly comorbid (Kofoed et al. 1993; Bremner et al. 1996; Stewart 1996; Keane and Kaloupek 1997; Kushner et al. 2000). Alcohol use following trauma or PTSD onset is often emphasized (Stewart 1996), but prior alcohol use likely increases PTSD risk (Keane and Kaloupek 1997; Kushner et al. 1999). We propose that adolescent heavy alcohol drinking impairs rapid fear discrimination, providing a potential mechanism by which adolescent drinking influences adult PTSD risk. Here, we have attempted to quantify the rapidity with which fear discrimination emerges in rats and its possible adult impairment in adolescent heavy alcohol drinkers.

Male, Long Evans rats were single-housed and given chronic intermittent access to alcohol (20\% ethanol, $n=29)$ or water $(n=$ 15; Supplemental Fig. 1) throughout adolescence (Fig. 1A) based on established, voluntary drinking procedures (Doremus et al. 2005; Simms et al. 2008). Food and water were available at all times, ensuring that alcohol drinking was not the result of caloric restriction or water deprivation. Heavy drinkers $(n=8$, Fig. 1B) were identified as rats whose mean alcohol drinking over the final four sessions was at least $10 \mathrm{~g} / \mathrm{kg}$ per $24 \mathrm{~h}$. This alcoholdrinking amount is comparable with the amount of drinking demonstrated by alcohol-preferring rat strains (Marchant et al. 2013), is double terminal alcohol-drinking amounts observed in adult long evans rats (Simms et al. 2008), and is similar to alcoholdrinking amounts necessary to observe positive alcohol reinforcement (DiLeo et al. 2015). To control for access to alcohol, the eight rats showing the lowest alcohol drinking were identified as mod-

\section{Corresponding author: michael.mcdannald@bc.edu}

Article is online at http://www.learnmem.org/cgi/doi/10.1101/Im.043257.116. erate drinkers (Fig. 1B). Although not anticipated, heavy drinkers gained weight less rapidly than controls during adolescence (Supplemental Fig. 2). However, as will be evident below, differences in body weight did not account for differences in rapid fear discrimination. After a brief abstinence period, behavioral training for fear discrimination began.

Single housing was maintained throughout adult testing. Rats were restricted to $85 \%$ of their free-feeding body weight and trained to nose poke in a central port to retrieve a food reward from a cup below (Fig. 1C). In the next two sessions, rats were preexposed to three auditory cues to be used in Pavlovian discrimination. Auditory cues used for fear conditioning were $10 \mathrm{sec}$ long and consisted of repeating, 500-msec motifs of a horn, siren, or broadband click. In the subsequent 16 discrimination sessions, each auditory cue was associated with a different probability of foot shock $(0.5 \mathrm{~mA}, 0.5 \mathrm{sec})$ : safety, $P=0.00$; uncertainty, $P=$ 0.25 ; or danger, $P=1.00$ (Fig. 1D). The physical identities of the cues were counterbalanced across each group. The foot shock was administered $1 \mathrm{sec}$ following the termination of the auditory cue. Importantly, the schedule for rewarded nose poking was completely independent from the presentation of auditory cues and foot shock. Accurate behavioral discrimination required the relative pattern of cued fear to reflect each cue's unique foot shock probability.

Fear was measured using suppression of rewarded nose poking (Estes and Skinner 1941; Pickens et al. 2009; QuinonesLaracuente et al. 2015; Wright et al. 2015), which permitted behavioral analysis in short temporal windows. Nose poke rates (pokes/min) were taken from two temporal windows: the 20-sec "baseline window" immediately prior to cue onset, and a "cue window" immediately following cue onset. The length of the cue window was incremented in $50 \mathrm{msec}$ steps from 50 to 2000 msec. A suppression ratio was calculated for each cue window from the nose poke rates as follows: ((baseline rate - cue rate)/ (baseline rate + cue rate)). A value of " 1 " indicated complete suppression of nose poking during the cue window, relative to

\footnotetext{
(C) 2016 DiLeo et al. This article is distributed exclusively by Cold Spring Harbor Laboratory Press for the first 12 months after the full-issue publication date (see http://learnmem.cshlp.org/site/misc/terms.xhtml). After 12 months, it is available under a Creative Commons License (AttributionNonCommercial 4.0 International), as described at http://creativecommons. org/licenses/by-nc/4.0/.
} 

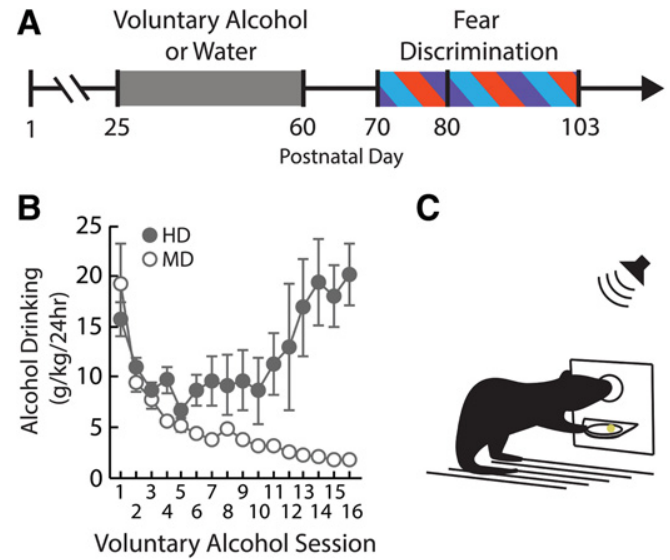

C
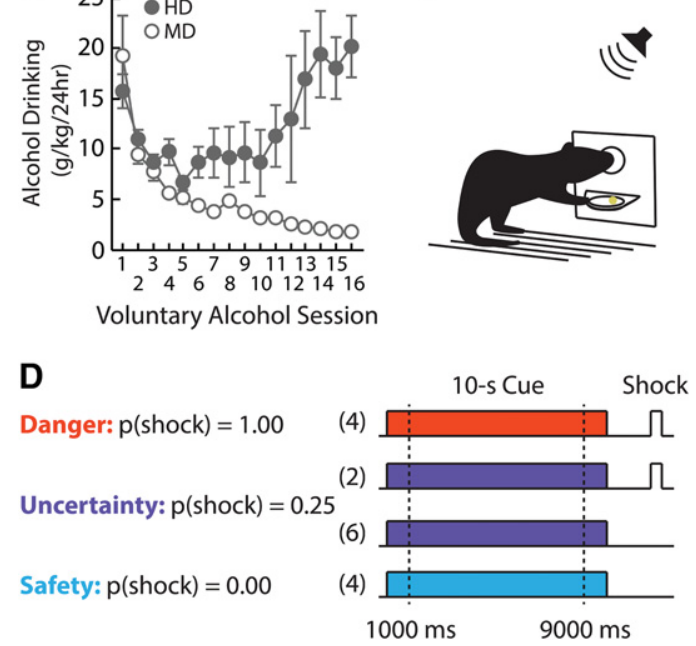

Figure 1. Experimental timeline, adolescent drinking, and Pavlovian fear discrimination procedure. (A) Starting postnatal day $25 \pm 1$, adolescent rats were given voluntary access to water or alcohol. Chronic access ended postnatal day $60 \pm 1$ and after a 10-d abstinence period, nose poke acquisition began. The first session containing foot shock occurred on postnatal day $80 \pm 4$, and training ended on day $103 \pm 4$. (B) Mean \pm SEM drinking $(\mathrm{g} / \mathrm{kg} / 24 \mathrm{~h})$ over the 16 sessions of chronic intermittent access is shown for heavy drinkers (HD, gray) and moderate drinkers (MD, open). (C) All rats were shaped to poke in a central port to retrieve food from the well below. During Pavlovian discrimination, auditory cues were presented using a speaker mounted to the ceiling of the sound attenuated chamber. Foot shocks were delivered through parallel metal bars comprising the floor. $(D)$ During Pavlovian fear discrimination, three cues signaled foot shock $(0.5 \mathrm{sec}, 0.5 \mathrm{~mA})$ with three different probabilities: safety, $P=0.00$; uncertainty, $P=0.25$; and danger, $P=1.00$. Number of trials per discrimination session is indicated in parentheses.

baseline, and high fear. A value of " 0 " indicated no suppression and no fear. Gradations between " 0 " and " 1 " permitted intermediate levels of cued fear to be measured.

Controls and heavy drinkers demonstrated equivalent baseline nose poke rates over the 16 sessions of fear discrimination (Fig. 2). In support, ANOVA comparing baseline nose poke rates for controls and heavy drinkers over the 16 discrimination sessions found an effect of session $\left(F_{(15,315)}=20.10, P<0.025\right)$, but no effect of or interaction with group ( $F \mathrm{~s}<0.2, P \mathrm{~s}>0.7)$. Similarly, controls and moderate drinkers also demonstrated equivalent nose poking levels with ANOVA finding no effect of group $\left(F_{(1,21)}=2.00, P=0.17\right)$ or group $\times$ session interaction $\left(F_{(15,315)}=0.52, P=0.92\right)$. Observing equivalent baseline nose poke rates is critical to the calculation of a suppression ratio, which compares nose poke rates during baseline and cue periods. This ensures that any differences in fear discrimination cannot be explained by differences in baseline nose poking.

The critical question is, from the time of cue onset, how rapidly can fear discrimination be detected? For this analysis, we focused on the final four of 16 discrimination sessions. In this study (Supplemental Fig. 3), as well as previous studies from our laboratory (Berg et al. 2014; Wright et al. 2015), rats demonstrated excellent discrimination during these final sessions. Starting with cue onset $(0 \mathrm{msec})$, a cumulative temporal window was incremented in $50 \mathrm{msec}$ steps to a maximum of $2000 \mathrm{msec}$ for a total of 40 temporal windows. Mean suppression ratios were calculated for each cue (safety vs. uncertainty vs. danger), and a repeated measures analysis of variance (ANOVA) with cue as the factor was performed for each window. The result was a significance map indicating the ANOVA $P$-value, revealing a main effect of cue for each of the 40 temporal windows (Fig. 3A).

Impressively, control rats showed evidence of fear discrimination in a 450-msec window (Fig. 3A, yellow area). Even when a more conservative significance threshold was adopted, subsecond fear discrimination was detected $(550 \mathrm{msec}$; Fig. 3A, orange area). At $1000 \mathrm{msec}$ (Fig. 3A, black line), the full pattern of discrimination was readily apparent: high fear to danger, intermediate fear to uncertainty, and low fear to safety. Discrimination was achieved rapidly and maintained for the remainder of cue presentation. When the final $8 \mathrm{sec}$ of the cue were analyzed in eight, 1000 msec windows, significant discrimination was observed in every window (Fig. 3B). Subsecond fear discrimination was also detected when sessions 9-12 were analyzed (Supplemental Fig. 4), although in a slightly longer temporal windows $(550 \mathrm{msec}$, $P<0.05 ; 750$ msec, $P<0.01)$, demonstrating rapid fear discrimination was acquired with training.

Having demonstrated robust evidence of subsecond fear discrimination in controls, we next asked if heavy drinkers possessed similar abilities. We applied the same temporal window analysis to the heavy drinkers to identify the shortest window in which fear discrimination could be detected. Remarkably, significant fear discrimination was not achieved in any temporal window of $2000 \mathrm{msec}$ or shorter (Fig. 3C), indicating a profound deficit in rapid fear discrimination. ANOVA significance in heavy drinkers was not obtained until $2150 \mathrm{msec}(P<0.05)$ or $2600 \mathrm{msec}$ following cue onset $(P<0.01)$, approximately four to five times longer than controls. Supporting this deficit, ANOVA for suppression ratios in the first $1000 \mathrm{msec}$ after cue onset [factors: group (controls vs. heavy drinkers), cue (safety vs. uncertainty vs. danger), session (13-16)] revealed a significant group $\times$ cue $\times$ session interaction $\left(F_{(6,126)}=2.87, P<0.025\right)$. The interaction was the result of controls, but not heavy drinkers, acquiring greater fear discrimination over the four sessions. Individual session suppression ratio data for each group over the 16 sessions of discrimination are shown in Supplemental Figure 3.

Specifically, heavy drinkers were unable to rapidly reduce fear to the safety cue, showing suppression levels equivalent to that of the uncertainty cue. In support, a within-subjects $t$-test

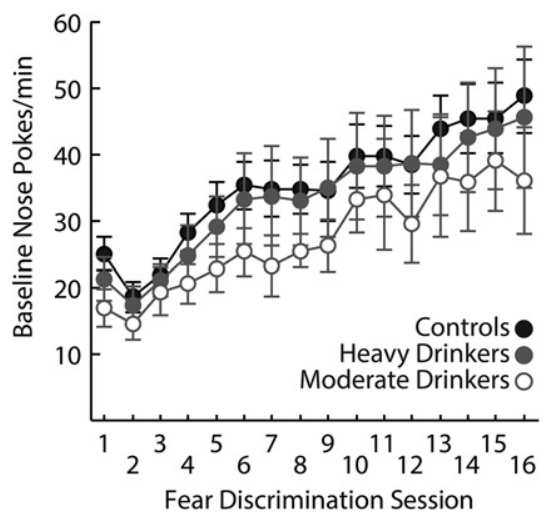

Figure 2. Baseline nose poke rates. Mean \pm SEM nose poke rate per minute during the baseline period for each session of Pavlovian fear conditioning is shown. "Baseline" is the 20 -sec period preceding cue onset and was used for the calculation of suppression ratios. For this figure, baselines were collapsed across all trial types, but for all analyses, each trial's own baseline was used to calculate the suppression ratio for that trial. 


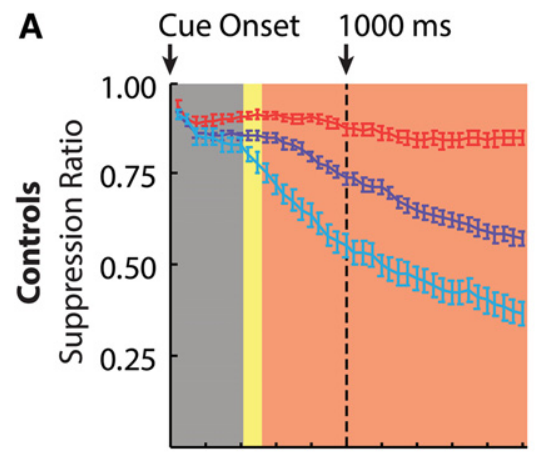

B
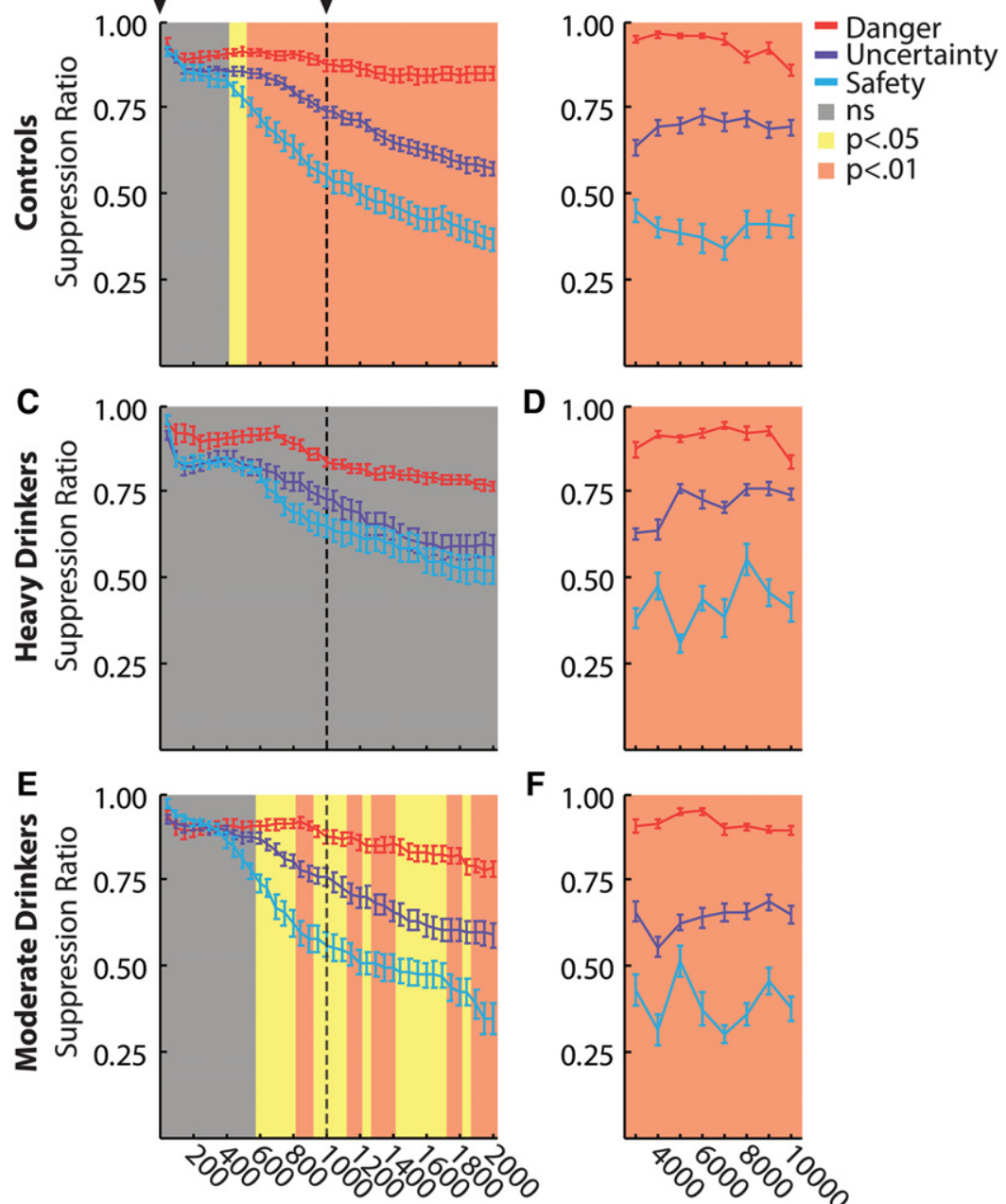

Cumulative Time (ms)

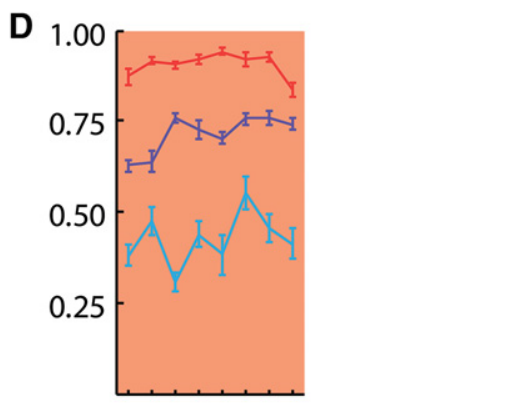

$\mathbf{F}$

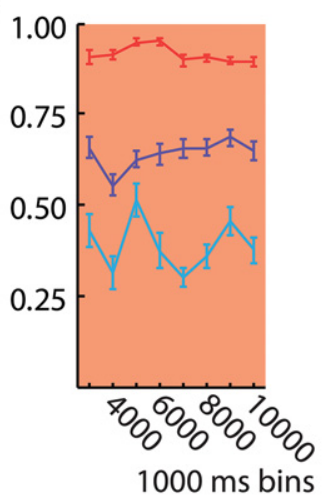

Figure 3. Rapid emergence of Pavlovian fear discrimination. (A) Suppression ratio data from fear discrimination are shown for control rats. Mean \pm SEM suppression ratios over the last four sessions for each cue (safety-blue, uncertainty-purple and danger-red) are plotted for cumulative temporal windows starting at cue onset and increasing by $50 \mathrm{msec}$ until a maximum of $2000 \mathrm{msec}$. The black dotted line indicates a temporal window of $1000 \mathrm{msec}$. For each window, a repeated measures ANOVA was performed with color indicating the significance of the main effect of cue $(P \geq 0.05-$ gray, $P<$ 0.05 -yellow and $P<0.01$-orange). (B) Mean \pm SEM suppression ratios for the final 8 sec of cue presentation were broken down into $1000 \mathrm{msec}$ bins, and an ANOVA was performed for each bin. (C) Suppression ratio data from fear discrimination are shown for heavy drinkers. (D) Mean \pm SEM suppression ratios for the final $8 \mathrm{sec}$ of cue presentation were broken down into $1000 \mathrm{msec}$ bins, and an ANOVA was performed for each bin. (E) Suppression ratio data from fear discrimination are shown for moderate drinkers. $(F)$ Mean \pm SEM suppression ratios for the final 8 sec of cue presentation were broken down into 1000 msec bins, and an ANOVA was performed for each bin.

restricted to the safety and uncertainty cues for the first $2000 \mathrm{msec}$ of cue sampling revealed no significant differences in heavy drinkers $\left(t_{(7)}=-1.49, P=0.17\right)$, whereas the same analysis found a significant difference in controls $\left(t_{(14)}=-3.15, P<0.05\right)$. Notably, heavy drinkers did not exhibit a general deficit, as significant discrimination was observed in each of the final eight, 1000 msec cue windows (Fig. 3D). In contrast to the ANOVA for the first 1000 msec following cue onset, ANOVA for the last $1000 \mathrm{msec}$ of the cue, with all other factors the same, revealed no significant group $\times$ cue $\times$ session interaction $\left(F_{(6,126)}=1.37, P=0.23\right)$, but a significant effect of cue $\left(F_{(2,42)}=3.57, P<0.025\right)$. Impaired rapid fear discrimination in heavy drinkers was not attributable to differences in body weight, as there was no correlation between body weight and rapid fear discrimination within any group or among all rats analyzed (Supplemental Fig. 5).

It is possible that the deficit we observed in heavy drinkers was due to a smaller sample size (controls, $n=15$ vs. heavy drinkers, $n=8$ ) or simple access to alcohol in adolescence. To control for this possibility, we performed an identical analysis on moderate drinkers $(n=8)$, equating for sample size and access to alcohol in adolescence. Moderate drinkers showed rapid emergence of fear discrimination following cue onset similar to controls (Fig. 3E). Subsecond fear discrimination was detected in moderate drinkers when using either standard $(600 \mathrm{msec}, P<0.05)$ or conservative significance thresholds (850 msec, $P<0.01)$. Significance was maintained for the remainder of the cue period with the $P$-level hovering around 0.01 (Fig. 3E, orange and yellow bars).

In support of rapid fear discrimination by moderate drinkers equivalent to that of controls, ANOVA for the first $1000 \mathrm{msec}$ after cue onset [factors: group (controls vs. moderate drinkers), cue (safety vs. uncertainty vs. danger), and session (13-16)] revealed no effects of or interactions with group ( $F \mathrm{~s}<1.4$, $P s>0.25)$, but found a significant effect of cue $\left(F_{(2,42)}=30.94, P<0.025\right)$. Moderate drinkers also maintained discrimination for the remainder of the cue (Fig. 3F). ANOVA for the last 1000 msec found no effects of or interactions with group ( $F \mathrm{~s}<1.4, P \mathrm{~s}>0.25)$, but a significant effect of cue $\left(F_{(2,42)}=43.90\right.$, $P<0.025)$. Thus, simple access to alcohol in adolescence was insufficient to impair rapid fear discrimination in adulthood. Rapid fear discrimination was also present in intermediate drinkers $(n=13)$, supporting our finding that adolescent heavy alcohol drinking selectively impaired subsecond fear discrimination (Supplemental Fig. 6). Finally, a comparison of adolescent alcohol drinking and adult rapid fear discrimination across all alcohol rats $(n=29)$ found that greater alcohol drinking was associated with a more restricted individual range of discrimination, as well as impaired discrimination (Supplemental Fig. 7).

Here we have demonstrated that rats can readily achieve subsecond fear discrimination. This is even more impressive considering discrimination required cued fear to differentiate between three probabilities of foot shock. After an extensive literature search, we were unable to find any previous study quantifying the rapidity of fear discrimination, much less a study reporting the emergence of fear discrimination on a subsecond time scale following cue onset. Our finding of an $\sim 450-550 \mathrm{msec}$ discrimination latency places normal fear discrimination abilities much closer to those observed for rapid perceptual decisions in vision 
and olfaction, which can reliably be observed in $\sim 200-300 \mathrm{msec}$ latencies (Uchida et al. 2006).

Adults with an adolescent history of heavy alcohol drinking were impaired in rapid fear discrimination. Remarkably, robust discrimination between all three cues was not observed until $>2$ sec following cue onset. The deficit largely stemmed from an inability to rapidly reduce fear to the safety cue. Indeed, fear reduction to the uncertainty cue was not grossly impaired. While speculative, this pattern may be observed because more inhibition is necessary to rapidly reduce fear to the safety cue to appropriate/ low levels.

The performance of heavy drinkers has parallels to individuals with PTSD, who demonstrate inappropriately high fear to safety cues in a discrimination setting (Jovanovic et al. 2011, 2013), with a caveat that the deficit in PTSD is unlikely to be restricted to cue onset. We propose that heavy alcohol-drinking adolescents are already at a behavioral and neural disadvantage in adulthood, as they are less able to rapidly and accurately discriminate dangerous from safe events. Traumatic experiences likely affect behavioral and neural systems already impaired in these individuals. Further, adolescent heavy alcohol drinking is associated with increased risk for traumatic encounters (Clark et al. 1997; Swahn et al. 2004). This may set in motion a cruel feedforward process in which heavy adolescent drinking simultaneously weakens neurobehavioral systems for rapid fear discrimination and increases the risk for traumatic experiences that can further weaken neurobehavioral systems for rapid fear discrimination.

Of course, the results do not require that adolescent heavy alcohol drinking induces impairment in rapid fear discrimination. It is possible that a predisposition for adolescent heavy alcohol drinking co-occurs with a predisposition for poor, rapid fear discrimination. Adolescent access to alcohol may only serve to reveal this predisposition. Even so, our results still require overlap in the neural and behavioral systems supporting alcohol drinking and rapid fear discrimination. It is further possible that deficits in rapid fear discrimination are not exclusive to adolescent alcohol drinking, and would be observed if heavy drinkers were identified in adulthood and subsequently tested in fear discrimination. However, even if adult access produced the same result, it would still be the case that adolescent heavy alcohol drinking impairs rapid fear discrimination in adulthood.

Our findings also do not preclude links between adolescent alcohol and other adult capacities pertaining to fear and anxiety. For example, adult rats with a history of adolescent binge drinking demonstrate increased exploration of open arms in the elevated plus maze. While this is consistent with a decrease in adulthood anxiety, it might also reflect an increase in risk taking (Gilpin et al. 2012). Adolescent alcohol experience has also been implicated in extinction and recall of fear in adult rats (Broadwater and Spear 2013, 2014) and mice (Holmes et al. 2012) as well as increases in other indices of anxiety (Vetreno et al. 2015). However, the differing methods used to induce alcohol experience and the varying indices of adult fear make broad conclusions about the full relationship between adolescent alcohol drinking and adult fear and anxiety premature.

Rapid fear discrimination provides a tool to uncover novel neural circuits critical to fear processing and their disruption by adolescent experiences associated with increased risk for anxiety disorders. While the amygdala (McDannald and Galarce 2011; Genud-Gabai et al. 2013; Sangha et al. 2013; Sciascia et al. 2015) is likely targeted by adolescent heavy alcohol drinking, broader amygdalocortical (Murray and Izquierdo 2007), and amygdalostriatal (Setlow et al. 2002; Millan et al. 2015) networks are almost certainly targeted. Mapping these neural circuits will be essential to uncovering how subsecond fear discrimination is normally achieved and how dysfunction contributes to maladaptive fear and perhaps anxiety disorders.

\section{Competing interest statement}

The authors declare no competing financial interests.

\section{Acknowledgments}

This work was supported by the National Institutes of Health (DA034010) (M.A.M.). We thank Dr. John Christianson and two anonymous reviewers for valuable comments on the manuscript. Author contributions: M.A.M. conceived and designed the experiment; M.A.M., A.D., and K.M.W. acquired the data; M.A.M., A.D., and K.M.W. analyzed and interpreted the data. M.A.M. drafted the manuscript that was then critically revised by M.A.M., A.D., and K.M.W.; all authors approved the submitted manuscript.

\section{References}

Berg BA, Schoenbaum G, McDannald MA. 2014. The dorsal raphe nucleus is integral to negative prediction errors in Pavlovian fear. Eur J Neurosci 40: $3096-3101$.

Bremner JD, Southwick SM, Darnell A, Charney DS. 1996. Chronic PTSD in Vietnam combat veterans: course of illness and substance abuse. Am J Psychiatry 153: 369-375.

Broadwater M, Spear LP. 2013. Consequences of ethanol exposure on cued and contextual fear conditioning and extinction differ depending on timing of exposure during adolescence or adulthood. Behav Brain Res 256: $10-19$.

Broadwater M, Spear LP. 2014. Consequences of adolescent or adult ethanol exposure on tone and context fear retention: effects of an acute ethanol challenge during conditioning. Alcohol Clin Exp Res 38: 1454-1460.

Clark DB, Lesnick L, Hegedus AM. 1997. Traumas and other adverse life events in adolescents with alcohol abuse and dependence. J Am Acad Child Adolesc Psychiatry 36: 1744-1751.

DiLeo A, Wright KM, Mangone E, McDannald MA. 2015. Alcohol gains access to appetitive learning through adolescent heavy drinking. Behav Neurosci 129: 371-379.

Doremus TL, Brunell SC, Rajendran P, Spear LP. 2005. Factors influencing elevated ethanol consumption in adolescent relative to adult rats. Alcohol Clin Exp Res 29: 1796-1808.

Estes KW, Skinner BF. 1941. Some quantitative properties of anxiety. J Exp Psychol 29: 390-400.

Genud-Gabai R, Klavir O, Paz R. 2013. Safety signals in the primate amygdala. J Neurosci 33: 17986-17994.

Gilpin NW, Karanikas CA, Richardson HN. 2012. Adolescent binge drinking leads to changes in alcohol drinking, anxiety, and amygdalar corticotropin releasing factor cells in adulthood in male rats. PLoS One 7: e31466.

Holmes A, Fitzgerald PJ, MacPherson KP, DeBrouse L, Colacicco G, Flynn SM, Masneuf S, Pleil KE, Li C, Marcinkiewcz CA, et al. 2012. Chronic alcohol remodels prefrontal neurons and disrupts NMDAR-mediated fear extinction encoding. Nat Neurosci 15: 1359-1361.

Jovanovic T, Norrholm SD, Blanding NQ, Davis M, Duncan E, Bradley B, Ressler KJ. 2010. Impaired fear inhibition is a biomarker of PTSD but not depression. Depress Anxiety 27: 244-251.

Jovanovic T, Phifer JE, Sicking K, Weiss T, Norrholm SD, Bradley B, Ressler KJ. 2011. Cortisol suppression by dexamethasone reduces exaggerated fear responses in posttraumatic stress disorder. Psychoneuroendocrinology 36: 1540-1552.

Jovanovic T, Ely T, Fani N, Glover EM, Gutman D, Tone EB, Norrholm SD, Bradley B, Ressler KJ. 2013. Reduced neural activation during an inhibition task is associated with impaired fear inhibition in a traumatized civilian sample. Cortex 49: 1884-1891.

Keane TM, Kaloupek DG. 1997. Comorbid psychiatric disorders in PTSD. Implications for research. Ann N Y Acad Sci 821: 24-34.

Kofoed L, Friedman MJ, Peck R. 1993. Alcoholism and drug abuse in patients with PTSD. Psychiatr Q 64: 151-171.

Kushner MG, Sher KJ, Erickson DJ. 1999. Prospective analysis of the relation between DSM-III anxiety disorders and alcohol use disorders. Am J Psychiatry 156: 723-732.

Kushner MG, Abrams K, Borchardt C. 2000. The relationship between anxiety disorders and alcohol use disorders: a review of major perspectives and findings. Clin Psychol Rev 20: 149-171. 
Marchant NJ, Khuc TN, Pickens CL, Bonci A, Shaham Y. 2013. Context-induced relapse to alcohol seeking after punishment in a rat model. Biol Psychiatry 73: 256-262.

McDannald MA. 2010. Contributions of the amygdala central nucleus and ventrolateral periaqueductal grey to freezing and instrumental suppression in Pavlovian fear conditioning. Behav Brain Res 211 : 111-117.

McDannald MA, Galarce EM. 2011. Measuring Pavlovian fear with conditioned freezing and conditioned suppression reveals different roles for the basolateral amygdala. Brain Res 1374: 82-89.

Millan EZ, Reese RM, Grossman CD, Chaudhri N, Janak PH. 2015. Nucleus accumbens and posterior amygdala mediate cue-triggered alcohol seeking and suppress behavior during the omission of alcohol-predictive cues. Neuropsychopharmacology 40: 2555-2565.

Murray EA, Izquierdo A. 2007. Orbitofrontal cortex and amygdala contributions to affect and action in primates. Ann N Y Acad Sci 1121: 273-296.

Pickens CL, Golden SA, Adams-Deutsch T, Nair SG, Shaham Y. 2009. Long-lasting incubation of conditioned fear in rats. Biol Psychiatry 65: $881-886$.

Quinones-Laracuente K, Hernandez-Rodriguez MY, Bravo-Rivera C, Melendez RI, Quirk GJ. 2015. The effect of repeated exposure to ethanol on pre-existing fear memories in rats. Psychopharmacology (Berl) 232: 3615-3622.

Sangha S, Chadick JZ, Janak PH. 2013. Safety encoding in the basal amygdala. J Neurosci 33: 3744-3751.

Schiller D, Levy I, Niv Y, LeDoux JE, Phelps EA. 2008. From fear to safety and back: reversal of fear in the human brain. J Neurosci 28: 11517-11525.

Sciascia JM, Reese RM, Janak PH, Chaudhri N. 2015. Alcohol-seeking triggered by discrete Pavlovian cues is invigorated by alcohol contexts and mediated by glutamate signaling in the basolateral amygdala. Neuropsychopharmacology 40: 2801-2812.

Setlow B, Holland PC, Gallagher M. 2002. Disconnection of the basolateral amygdala complex and nucleus accumbens impairs appetitive Pavlovian second-order conditioned responses. Behav Neurosci 116: 267-275.

Simms JA, Steensland P, Medina B, Abernathy KE, Chandler LJ, Wise R, Bartlett SE. 2008. Intermittent access to $20 \%$ ethanol induces high ethanol consumption in Long-Evans and Wistar rats. Alcohol Clin Exp Res 32: 1816-1823.

Stewart SH. 1996. Alcohol abuse in individuals exposed to trauma: a critical review. Psychol Bull 120: $83-112$.

Swahn MH, Simon TR, Hammig BJ, Guerrero JL. 2004 Alcohol-consumption behaviors and risk for physical fighting and injuries among adolescent drinkers. Addict Behav 29: 959-963.

Uchida N, Kepecs A, Mainen ZF. 2006. Seeing at a glance, smelling in a whiff: rapid forms of perceptual decision making. Nat Rev Neurosci 7: $485-491$.

Vetreno RP, Yaxley R, Paniagua B, Crews FT. 2015. Diffusion tensor imaging reveals adolescent binge ethanol-induced brain structural integrity alterations in adult rats that correlate with behavioral dysfunction. Addict Biol 21: 939-953.

Wright KM, DiLeo A, McDannald MA. 2015. Early adversity disrupts the adult use of aversive prediction errors to reduce fear in uncertainty. Front Behav Neurosci 9: 227.

Received June 22, 2016; accepted in revised form July 28, 2016. 


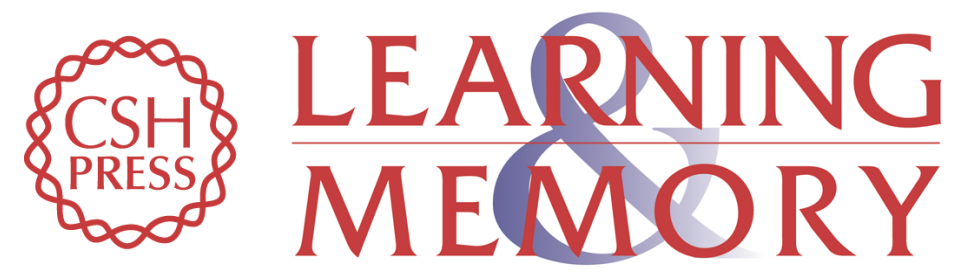

\section{Subsecond fear discrimination in rats: adult impairment in adolescent heavy alcohol drinkers}

Alyssa DiLeo, Kristina M. Wright and Michael A. McDannald

Learn. Mem. 2016, 23:

Access the most recent version at doi:10.1101/Im.043257.116

\section{Supplemental http://learnmem.cshlp.org/content/suppl/2016/10/06/23.11.618.DC1 Material}

References This article cites 35 articles, 3 of which can be accessed free at: http://learnmem.cshlp.org/content/23/11/618.full.html\#ref-list-1

Creative This article is distributed exclusively by Cold Spring Harbor Laboratory Press for the Commons first 12 months after the full-issue publication date (see

License http://learnmem.cshlp.org/site/misc/terms.xhtml). After 12 months, it is available under a Creative Commons License (Attribution-NonCommercial 4.0 International), as described at http://creativecommons.org/licenses/by-nc/4.0/.

Email Alerting Receive free email alerts when new articles cite this article - sign up in the box at the Service top right corner of the article or click here. 